\title{
Dissonância cultural? o trabalho em Brasília*
}

\author{
Cultural dissonance? the work in Brasília
}

\author{
Marcia de Melo Martins Kuyumjian**
}

RESUMO

Utilizamos a imagem da orquestra para considerar o sentido de dissonância e suas variações na complexidade do entendimento da Brasília informal, ao investigarmos o trabalho e suas manifestações a partir do viés cultural. Consideramos que no cotidiano do trabalho, percepção e sensibilidade se alinham para redimensionar a dissonância como um arranjo da diversidade do fazer e pensar em sociedade. É essa dissonância que permite mesclar diferentes tipos de trabalho que, embora estratificados e numa escala de valores bem demarcada pelos setores hegemônicos, nos oferece a dinâmica social, incrustada na história e nas formas como a socialidade imprime sua marca no que é popular. Dionisíaca é a vida experimentada no universo do trabalho informal, também um desconcerto, um arranjo sonoro que vibra em outra escala. É o lugar da ipseidade, da narrativa que toma outro lugar de fala e dá margem a estratégias de interação, de liberdade e de ação dos atores jogadores. É a identidade de si. Assim, o termo informalidade traz em si um desconforto, mas também revela que os espaços da cidade de Brasília são lugares praticados, onde experiências e solidariedade são reativadas diuturnamente. Para tanto, escolhemos enfatizar as falas e as imagens que emergem dos trabalhadores informais que ocupam diferentes espaços da cidade. Resultado de pesquisa com o apoio do CNPq, iniciada em 2007, na qual foram entrevistados mais de 40 trabalhadores e organizado um arquivo com quase 2 mil fotos.

PALAVRAS-CHAVE: Trabalho informal - KEY-WORDS: Informal work - Brasília.

Brasília. Dissonância cultural - Identidade - Cultural dissonance - Identity - Research

\section{ABSTRACT}

We used the image of the orchestra to consider the meaning of dissonance and its variations in the complex understanding of the informal Brasilia, in the investigation of the work and its manifestations in a cultural bias. We consider that, in the daily work, insight and sensitivity are aligned to resize the dissonance as an arrangement of the diversity of doing and thinking in society. It is this dissonance that permits the merging of different types of work that, although stratified on a scale of values well defined by hegemonic sectors, gives us the social dynamics, embedded in history and in the ways which sociality prints its mark on what is popular. Dionysian is the life experienced in the universe of informal work, also uneasiness, a sonorous arrangement that vibrates at a different scale. It is the place of selfhood, narrative that takes other speech place and gives rise to strategies of interaction, freedom and action for the players. It's the identity of oneself. Thus, the term informality carries with it a discomfort, but also reveals that the spaces of the city of Brasilia are practiced places, where experiences and solidarity are reactivated every day. To do this we chose to emphasize the words and images that emerge from informal workers who occupy different spaces in the city. This work is a results of a research, supported by CNPq, that begun in 2007, with more than 40 workers interviews and a file with almost 2 thousand pictures.

\footnotetext{
* Agradeço ao CNPq, pelo apoio para a realização desta pesquisa, e à UnB, por possibilitar a apresentação deste trabalho no V Simpósio Internacional de História: Cultura e Identidades, em 2009, na cidade de Goiânia/ GO.

** Universidade de Brasília. Email: marciak54@brturbo.com.br
} 
Compreender o mundo do trabalho em Brasília é estar atento à complexidade da contemporaneidade, cujos apelos econômicos, sociais e culturais descarregam energias múltiplas em várias direções.

A imagem de uma orquestra é bastante ilustrativa dessa complexidade. Vejo-a como uma metáfora que nos coloca em sintonia com o intricado mundo do trabalho na contemporaneidade. Observando-a, verificamos que compete ao maestro marcar o tempo e o ritmo de cada instrumento. De pouco valeria seu esforço se a batuta não funcionasse como mediadora, ou seja, detentora de códigos que os músicos utilizam para se manter como um conjunto de sonora harmonia, em comunhão de individualidades instrumentais que buscam a perfeição tonal na ideia de unidade: a orquestra.

Os sons, mesmo que desarmônicos, como na escala gregoriana do jazz, não deixam de produzir um efeito sonoro que se aproxima da beleza que também a dissonância produz. Em princípio, essa dissonância ${ }^{1}$ se refere ao conjunto de sons que destoam entre si, como desafinação ou desentoação. Seria uma irresolução harmônica que remete à má combinação de cores, à falta de proporção nas formas, à desarmonia entre as partes. Em linguagem, a isso se denomina cacofonia ou assonância. No entanto, as rimas poéticas que se baseiam apenas na similaridade entre suas vogais podem, igualmente, produzir um belo efeito sonoro. Portanto, são os maus sons que agridem a sensibilidade auditiva e que refletem a ideia de dissonância, mas não a desarmonia, propriamente dita. Ao contrário, na música, na vida e no trabalho, essa dissonância vai assumir a harmonia que a orquestra consegue produzir, pois os instrumentos se solidarizam para compor a sonoridade.

Nesse sentido é que os seres humanos, no cotidiano do trabalho, utilizando também dessa mesma percepção e sensibilidade, conseguem traduzir o que parece feio em ato de beleza e coragem. A dissonância é, portanto, a marca do convívio em sociedade, onde pluralidade de intenções e gestos se mesclam, criando a musicalidade da "socialidade" (MASFFESOLI, 1997), do aprender a conviver na diferença.

Como transpor esse sentido de dissonância das sensações fisiológicas, sensitivas, para o mundo externo, o universo cultural? Antes de responder a essa pergunta, deve-se considerar o termo "cultura”, sem a pretensão de esgotar sua amplitude, como se referindo a

\footnotetext{
${ }^{1}$ Remeto-me ao verbete "dissonância" do dicionário Aulete Caldas on-line para discorrer sobre o sentido que desejo adotar ao termo neste texto.
} 
[...] atividades determinadas do ser humano que, no entanto, não se restringem às tradicionais (literatura, pintura, cinema - em suma, as que se apresentam sob uma forma estética), mas se abrem para uma rede de significações ou linguagens incluindo, tanto a cultura popular (carnaval), como a publicidade, a moda, o comportamento (ou a atitude), a festa, o consumo, o estar-junto, etc. (COELHO, 1997, p. 104)

Assim, na escala social, o campo cultural abrange os produtos materiais e imateriais populares e aqueles de territórios selados pela distinção. Classes populares e elite se entrecruzam ou, como prefere Bakhtin, ambos estão numa relação de circularidade. Entretanto, circularidade e "estar-junto" em Brasília não se estruturam em torno de identidades fixas e integradas à cidade, nem na direção da afirmação de grupos pela localização no mundo do trabalho, isto é, pela uniformidade de ofícios e tarefas identificadas como trabalho.

Ao utilizar a metáfora "Tudo que é sólido se desmancha no ar", Marx fez uma forte crítica à política e ideologia capitalistas, mas suas concepções contaminaram também o entendimento de cultura, sujeito, identidade e trabalho. O imaginário social ancora-se, aqui, na imagem do mundo movente, do ser humano narcisista e individualista. Essa metáfora revela a ambivalência da dialética moderna da qual nem o próprio Marx escapou. A convicção no progresso contaminou todo o século XIX, inclusive Marx, que reconhecia o importante papel das elites na condução da sociedade à modernidade, mas, ao mesmo tempo e, contraditoriamente, vaticinava a classe operária como a portadora de uma nova sociedade, que domesticaria a história contra sua efemeridade.

A leitura que Berman faz da obra de Marx é balizada pela metáfora marxista, reveladora do conflito entre duas visões, isto é, "tensão entre a visão 'sólida' e a visão 'diluidora' de Marx sobre a vida moderna' (BERMAN, 1986, p. 89). Tal leitura está vinculada à história cultural pela riqueza imaginativa que faz com que pensadores, trabalhadores, governantes, movimentos sociais, instituições compartilhem ritmos e energias fundadoras e organizadoras do social, mas também mudem prontamente de tom e inflexão quando a causa pela qual se luta não mais comporta inteligibilidade sociocultural. $O$ espectro de vozes se alarga e a harmonia e as dissonâncias formam o par que expressa o mundo impregnado por forças contrárias. Inevitavelmente, somos conduzidos a refletir sobre o lugar da racionalidade envolvida pela crença de que a razão domina a construção do mundo. A leitura de Berman remete-nos à crítica da razão expressa na imagem de Nietzsche diante do livro 
O mundo como vontade e o mundo como representação de Schopenhauer, descrita por Jair Barbosa na apresentação, como embriaguez, o que "traduz boa parte da experiência de desconcerto e deslumbramento vivida" diante da impotência humana que "perde a proteção da faculdade racional, e os demônios do mundo são revelados, vê-se nitidamente o inferno do sofrimento e da irrazão, comprovados pelas guerras e violências em seus aspectos mais tenebrosos". (BARBOSA, 2005, p. 9)

Se o enfraquecimento da razão leva ao sofrimento das guerras e violência na perspectiva de Schopenhauer, na de Marx, o sofrimento é desencadeado pela impossibilidade de domar a ambição humana que promove desenvolvimento, mas ao custo da exploração do trabalho humano. Esta breve referência não tem a pretensão de avançar no debate filosófico sobre vontade e razão, mas a de alinhavar encruzilhadas nas tramas do pensamento que conduzem ao lugar do trabalho no movimento histórico.

Assim, a ideia de dissonância que adoto coloca em evidência os caminhos da própria cultura, pois trabalho não se restringe a um ato, ao fazer, mas está carregado de conotações temporais conforme a lógica produtiva que alimenta o imaginário social em diferentes tempos. Vale relembrar que, enquanto Marx, no século XIX, denunciava os privilégios do capital contra o trabalho, no século XX assistiu-se ao esfacelamento do trabalho entre uma elite de profissionais superespecializados e uma massa de trabalhadores precarizados (MARX, 2005).

Consequentemente, o alvorecer do século XXI é contemplado com a imagem de que o trabalho perdeu status social, usurpado pelos delírios do mercado detrator do humano e estimulador do impulso compulsivo do consumo vazio. Aparentemente, estamos construindo imagens descoladas, uma vez que as prateleiras das lojas e as gôndolas dos supermercados não se autoabastecem. Há, e Marx já o anunciava, o trabalho humano real, resultado de horas de envolvimento com a produção. Contudo, a impressão éa de que o real é produto do virtual, pois o produto é apresentado de tal modo desvinculado da produção que trabalho e trabalhador não aparecem como partes harmônicas, em sintonia no processo produtivo.

O consumo tornou-se o bálsamo do indivíduo, viseira que inibe a crítica social e a adesão a uma causa política. Por outro lado, tem-se a impressão de que os trabalhadores já não se envolvem afetivamente com a empresa. Eles cantam e dançam em espaços diferentes daqueles que a empresa desejava. Além disso, os trabalhadores, entre si, formam grupos, como uma orquestra de interesses que lhes são próprios e em que, por vezes, a dissonância torna-se assonância, ou ainda, ruído sem sentido.. Rompe-se, assim, a comunicação entre eles e a empresa. É a prevalência do domínio da indiferença, no qual os 
trabalhadores pouco reivindicam em relação ao seu reconhecimento social como trabalhadores. O princípio da indiferença com o sistema produtivo informa que o trabalhador não é mais movido pela vontade de ser reconhecido por sua obra, mas por sua inserção no mundo do consumo. A vida privada assume, nesse novo cenário, papel principal, lugar do prazer onde se desfrutam as comodidades que a tecnologia oferece. Assim, as causas coletivas, esvaziadas de sentido devido à instrumentalização do social, são solapadas pelas lutas por interesses individuais.

Na concepção de Touraine (1994), reside aí a força libertadora da modernidade, que coloca em ênfase as lógicas de ação que se deslocam do agente social para o campo da subjetividade, isto é, a passagem do sujeito agindo em nome da coletividade ou da vontade geral para o indivíduo movido pela liberdade de exprimir desejos e instintos. A libido humana abre um profundo conflito com o mundo da lei e, ao mesmo tempo, esbarra na pressão das necessidades. Para Schopenhauer, o mundo da razão e da técnica é o da dessocialização, porque alimenta o egoísmo; para Freud, o ego (interiorização das normas) é o ponto de equilíbrio entre o id (império do desejo) e o superego (mecanismo de controle social que opera pela repressão). Então, a lei inculca valores e os indivíduos se subordinam aos interesses da sociedade, e a dissonância gregoriana já não conversa mais com o jazz. É pela conjugação dessas forças oponentes - prazer e lei - , pelo embate entre elas, que se faz, do ser humano, um ser social que busca reatualizar, cotidianamente, a harmonia do gregoriano do jazz. (HOBSBAWN, 1990)

Esta análise não é mera convenção, como não o é a natureza da sociedade capitalista. Informados por esta perspectiva, pensadores colocam, de um lado, o indivíduo libidinoso e, de outro, a disciplina social a partir da qual o trabalho é concebido e construído como um bem social. Marx, por exemplo, via a estrutura capitalista fundada na dicotomia do desejo da burguesia e da disciplina e subordinação do operário. Enquanto esse filósofo via o operariado como o portador da igualdade, da fraternidade e da liberdade dos homens em sociedade, a reestruturação produtiva o metamorfoseou em portador da ascensão ao paraíso da desigualdade social.

Contudo, para além de visões extremadas de pessimismos ou ilusões, a contemporaneidade, batizada por diversas designações - pós-industrial, pós-moderna, neoliberal, pós-neoliberal, de consumo, globalizada, virtual, sociedade industrial moderna , não se liberta da necessidade do trabalho. Parte do movimento histórico está presente em qualquer formação social e é, ao mesmo tempo, uma produção social. Este ponto cardeal da modernidade fracionada colocou em lados distintos o ato de trabalhar e a concepção de trabalho, o trabalho e o trabalhador, o mundo objetivo e o subjetivo do trabalhador. Esse é um dos efeitos das transformações ocorridas na sociedade, na ciência e nos padrões 
tecnológicos ao longo do século XX, principalmente com o advento da reestruturação produtiva produzida a partir da década de 70 .

Assim, o mundo do trabalho, pensado em Marx como uma unidade evocada na expressão "trabalhadores do mundo, uni-vos", perdeu sentido, pois a ambiguidade cravou o coração dessa noção. De que trabalho se está falando? Pergunta que precisa ser cuidadosamente investigada, afinal, será que o entendimento sobre o trabalho é o mesmo para todas as pessoas? ${ }^{2}$ Aparentemente, hoje, a apreensão do trabalho existe também na mesma perspectiva que existia na antiguidade, como fazendo parte dos costumes ordinários, como assevera Bouvier, da repetição do gesto como uma permanência temporal de reidentificação constante e invariável consigo mesmo. Eis uma revelação forte da ipseidade.

Não há, portanto, uma ordem estável e substancial de constituição do sujeito, uma espécie de atribuição colada a um destino metafísico, mas uma dinâmica de interiorização de comportamentos, atitudes e costumes a partir de padrões significativos no ambiente familiar e social. A identificação é fator dinâmico de integração do indivíduo no grupo e de mobilização de suas pulsões, afetos, escolhas. Implica, assim, tanto um ato social como privado (BOUVIER, 1991, p. 40).

Assim, narrativa é o lugar da ipseidade, pois dá margem a estratégias de interação, de liberdade e de ação dos atores jogadores. "A identidade de si ou ipseidade constrói-se em relação com a alteridade, isto é, num jogo movimentado por aparências diversas, sem lugar para a certeza cartesiana quanto à estabilidade lógica do sujeito da consciência” (SODRÉ, 1999, p. 45).

Desse modo, o trabalho, diz Morin (1982), visto como racional, convive com o risco de estar envolvido no círculo vicioso das lógicas superficiais e ser asfixiado por um racionalismo estreito demais, submetido à vontade da economia de mercado. A acuidade do olhar mais atento à diversidade e à variedade de manifestações do trabalho o colocará também atrelado ao reino da desordem. Esse é o mundo mágico que faz parte da realidade social, por sua força representacional que inaugura e assegura lugares, valores, normas e práticas socioculturais. Assim, o real e o imaginário confluem para territórios que tendem a ser mal decifrados, zonas sombrias da nossa civilização que conduzem a uma ancestralidade ancorada em mitos "que não são meras fantamagorias" (CASSIER, 2006, p. 36), mas compõem o universo humano, permitindo ordenar, classificar e compreender o mundo do objeto. O mito é, nesse contexto, o lugar do encontro entre a consciência ea psique.

\footnotetext{
2 Faço esta ressalva porque, na pesquisa de doutorado com os garimpeiros, chamou-me a atenção o depoimento que era mais um lamento pelo insucesso de se conseguir uma aposentadoria pelo INSS (ou, nos termos do próprio garimpeiro, "ser encostado") porque, assim, o dinheiro de que precisava para viver o deixaria livre para trabalhar.
} 
Esse tema é importante para minha reflexão porque procuro denotar o trabalho para além da imagem de sua materialidade dialética. $O$ trabalho é um desses territórios, essencial, mas mantido sob severo controle e hierarquia, pois, desde o advento do capitalismo, ele assume papel central na ordem social, mas também é uma ameaça porque abre novos campos representacionais por apropriações e ressignificações da produção e do consumo. É a dissonância que confronta a ordem. Logo, trabalhar é mais que um gesto. É um campo simbólico refinado em que apagamentos, memórias e novas escritas formatam uma complexa rede de sentidos. E vale, neste caso, considerar o que diz Cassirer:

Tem-se repetido freqüentemente que o mito e a religião são produtos do medo. Mas o que é mais importante na vida religiosa do homem não é o fato do medo, mas a metamorfose do medo. O medo é um instinto biológico universal. Não poderá nunca ser completamente vencido ou suprimido, mas pode mudar de forma. O mito está cheio das mais terríveis visões e das mais violentas emoções. Mas com o mito o homem começa a aprender uma nova e estranha arte: a arte de exprimir, e isso significa organizar os seus instintos mais profundamente enraizados, as suas esperanças e temores. (CASSIER, 2006, p. 64)

Como na melodia dissonante, o trabalho transforma o medo em inspiração para uma nova investida diante da adversidade.

Hoje, os sentidos construídos sobre o trabalho são fruto da combinação do gesto e do avanço técnico, cujo princípio primeiro é o de ativador e de poupador da energia humana, arrefecendo a dureza da vida in natura. Desde o advento do capitalismo, o trabalho desempenha papel central na ordem social, mas o faz por sua própria negação, pois o avanģo da técnica vem acompanhado da tentativa de apagamento dos velhos gestos do trabalho, do esvaziamento simbólico que liga o trabalho à vida eà morte. Trabalhar é, pois, o ato de realizar, produzir, tendo por referência o conhecimento sociocultural acumulado e a habilidade de conectar o ato de pensar com o de realizar. É atribuir vida a si e ao mundo à sua volta. É recriar o mundo da ancestralidade pela memória, pelos vestígios passados e os que pertencerão ao futuro. É dar ao filho a sábia ideia de que a marcha da humanidade continuará.

Uma vez compreendido o estatuto cultural do trabalho, vale recorrer a Baudrillard (1976), que critica a evolução tecnológica pelo fato de perceber a crença da sociedade ocidental em eliminar o universo simbólico pela apropriação dos objetos, pela produção e circulação de mercadorias. O trabalho é, ainda, um ethos humano que D'Épinay (1994) denomina de sincretismo ocidental por se transformar no coração da cultura ocidental.

As atividades pouco valorizadas pelo sistema feudal - comércio e artes - são apoderadas pelo burguês, que promove uma verdadeira revolução na conœepção de trabalho 
ao deslocá-las para as cidades, desenvolvendo ferramentas e livros de controle da produção, do fluxo de capitais e do tempo de trabalho pelo uso do relógio, este, o grande signo desta nova era, que assume o lugar central nas torres das igrejas e ditam o ritmo aos trabalhadones. A aventura humana, então, deixa de ser a cruzada e torna-se o trabalho, pelo qual o burguês afirma seus domínios, transformando o trabalho em um novo ator social.

Retomando a questão da necessidade e da utilidade em confronto com a vontade e a liberdade, citamos Monneyron e Renard (LEGROS et al., 2007, p. 98), para quem, esvaziar o "gesto tradicional do trabalho" é um esforço das instituições hegemônicas de adequar o simbólico ao funcional, retirando-lhe o sentido sagrado. Porém, como bem mostrou D'Epinay (1994), o trabalho é também um ato litúrgico, um sacramento que toma como referência o badalar do sino da igreja na Idade Média, afinal, a classe operária tem seus antecedentes nos campos e nos trabalhos rurais. Os muros dos antigos mosteiros guardavam a ritualística da integração e harmonização entre o humano e a natureza, e cada estação do ano era celebrada como uma obra divina. Daí, orar e trabalhar como as máximas da vida monacal beneditina.

Resiste a ideia de que é somente com o trabalho separado do labor cotidiano que o trabalho tem autonomia, desvinculando-se da necessidade de sobrevivência. No entanto, Sahlins (1976) percebeu que a base da economia primitiva não se detinha apenas à situação de carência física e espiritual. Eram relevantes também as práticas de repartição, o dom, a reciprocidade e a redistribuição. Porém, como bem assinalam Monneyron e Renard, a "liturgia formal do objeto" (LEGROS, 2007) conduz Baudrillard a interrogar a ilusão econômica que procede de uma concepção puramente materialista de troca social. $\mathrm{O}$ imaginário da economia é o último avatar da metafísica ocidental, construída sobre a simulação de uma finalidade universal de cálculo e de racionalidade produtiva.

A burguesia arrebatou a mão de obra dos trabalhadores rurais e instituiu a religião profana do trabalho sem o compromisso com o sagrado. Esse novo trabalhador sem a melodia dos sinos das torres, despido de sonoridade, torna-se uma reserva comportamental para os privilégios do reino dos homens. Racionalidade e cidadania tornam-se os detentores da civilização ornados pelo trabalho. A Revolução Industrial foi o baluarte da construção de uma nova musicalidade, cujo maestro é a empresa e os trabalhadores, excluídos dessa orquestra, assistem, enquanto trabalham, o regozijo dos detentores do poder que produzem sua própria harmonia social.

No entanto, o risco do excesso de racionalização é o de reduzir o mundo a categorias econômicas, políticas e intelectuais esvaziadas de sentido humano. Alinhavar esses pensamentos permite reiterar o caráter neutro do termo "trabalho", que é utilizado para legitimar ou negar determinados fazeres. Cultura, cotidiano, experiência e comunidade são 
noções que se articulam para mostrar que o trabalho tem valor como produtor de significados para os envolvidos com um fazer que confira sentido ao grupo eà existência. $\mathrm{Na}$ escala de valorização social, encontramos o artesão, os trabalhadores pouco qualificados e aqueles hiperqualificados, formatando um mundo cada vez mais complexo, como já salientei em outro texto (KUYUMJ IAN; LINS, 2008).

Veyne (1989) foi perspicaz em identificar, na gama de atividades laborais, a dificuldade de classificar aquelas que são consideradas produtivas pelos padrões estabelecidos pela economia de mercado. A realização pessoal, nessa nova ordem de redefinição das atividades produtivas, não deixa espaço para a realização pessoal pelo trabalho. Além disso, muitas atividades perdem sua funcionalidade econômica. As oficinas artesanais foram substituídas pelas atividades industriais; estas foram submetidas às profissões que, por sua vez, foram hierarquizadas segundo o grau de especialidade, incluindo o domínio da produção virtual. Com esta complexidade do mundo do trabalho, fica cada vez mais difícil classificar os negócios, os ofícios, as profissões liberais e os gestores públicos.

Assim, abrigado sob o leque do movimento histórico e dos movimentos sociais, um antropossocial e outro mais conjuntural e circunscrito, o trabalho adquire dois significados: trabalho-emprego e trabalho-cultura. O primeiro é fruto da redução da noção de trabalho à de emprego, entendido como assalariamento com regulação estatal. O segundo

se configura como uma prática cultural, da apropriação dos habitus familiares e comunitários. São atividades que permitem também localizar as práticas cotidianas familiares, tais como aprender a cuidar da casa, o ofício do pai, e ainda lidar com situações corriqueiras. Por conseguinte, oferece a oportunidade aos jovens das camadas populares de apreender valores e significados que funcionam como aprendizagem para a vida em sociedade (KUYUMJ IAN, 2003b, p. 248).

Essa categorização, de um lado, salienta os atributos indispensáveis ao salário e, de outro, os atributos indicadores do ethos da realização (D’EPINAY, 1994).

Retornando a Brasília encontramos, nestes primeiros anos do século XXI, trabalhos que pareciam existir apenas em registros memoriais do passado. Contudo, lá estão eles, competindo pelo espaço urbano com os profissionais liberais, gestores públicos, políticos e comerciantes. A cidade, hoje, carece de uma planta industrial e sua vocação administrativa divide o espaço com uma variedade de atividades de pouca relevância para o PIB. Nesse contexto, alguns tipos de trabalho não foram confiscados como um bem do capitalismo e subsistem alimentados pela simplicidade apreendida na tradição e na herança das práticas culturais. 
Na capital do país, entre os entrevistados na informalidade, no ano de 2009, os vendedores de frutas, de doces, de verduras, de churrasquinho, modo geral, vêm de linhagens familiares nas quais essas atividades já eram praticadas. Normalmente, referem-se a outros pontos de vendas que são ocupados pelo pai, irmão ou tio. Encontramos situações em que três gerações se revezam nos pontos de vendas, constituindo a principal atividade remunerada da família. O mais velho, líder do grupo, fica atento à oportunidade de abrir outros pontos, nos quais, ao se estabelecer, não abandona o anterior, repassando-o a um filho ou sobrinho para garantir trabalho à geração seguinte.

Dever e satisfação mais uma vez se fazem presentes no debate, porque a ambiguidade que ronda o termo "trabalho" persiste e podemos averiguar, in locus, sua formatação e complexidade para conferir o peso que o imaginário do trabalho-emprego e do trabalho-cultura tem na urbe. Evoco, novamente, Brasília, patrimônio cultural da humanidade e síntese política do Brasil. Embora representação modelar do mundo futuro, essa cidade não se liberta de velhas práticas ocupacionais que se imiscuem no seu cenário arquitetônico. Das tendas de artesãos, do perambular de ambulantes, dos lugares cativos de chaveiros, sapateiros e vendedores de frutas, inúmeras manifestações proliferam nos seus contornos nada convencionais.

O que Brasília, como cidade, possui de grandiosa, os homens e mulheres que a habitam possuem de corriqueiro. A costureira dos reparos e ajustes, os chaveiros e sapateiros, os vendedores de frutas e flores, os encanadores e eletricistas, os prestadores de serviço domésticos que se estabelecem nas entradas das quadras residenciais, afixando varais, os quiosques mal-ajambrados que fornecem refeições a preços módicos, nenhum deles se rendeu às grandes firmas que ofertam os mesmos serviços. Pode-se denominar esse fenômeno de dissonância cultural? Se há algum desconcerto nesse fato, ele se aloja no cruzamento da ação política de investir na cidade imagem do coletivo nacional e na ação da cultura do indivíduo trabalhador que constrói a cidade que lhe confere identidade.

Brasília, muito jovem, que acaba de completar cinquenta anos, tem sua identidade posta em questão, pois, na miscelânea de modos de ser e de fazer, na confluência de interesses múltiplos, é apreendida como descaracterizada culturalmente, sem um povo e uma identidade próprios. Porém, ela carrega consigo uma infinidade de experiências que, embora recolhidas alhures, é no seu solo que adquirem feições particulares. De outro modo dito, é ali, no coração da cidademonumento, cidade capital do país e cidade patrimônio da humanidade que ainda 
perambulam velhas práticas em um cenário que é (ou deveria ser) a expressão magna do que há de mais inovador, do olhar posto no futuro grandioso da nação brasileira.

Cidade administrativa, Brasília recebe, desde seus primeiros dias, personalidades renomadas, nacional e internacionalmente, mas também congrega uma miríade de manifestações e condições engendradas no solo histórico. São os que vieram acalentados pelo sonho da construção de uma grande cidade, sem os pecados ou tormentos das velhas e viciadas metrópoles; são os recém-chegados de diferentes regiões do país e alhures, com os mais variados propósitos, da casa própria ao concurso público. A estes, juntam-se os antigos moradores da região, como significativa confluência dos estados de Goiás, Minas Gerais, Tocantins e Mato Grosso, ajudando a compor o espaço hospedeiro dos memoráveis hábitos rurais, característicos do centrooeste do país.

Há o entendimento da existência, não apenas em Brasília, mas em todo o espaço territorial do Distrito Federal, de múltiplas e cambiantes formas de ser e estar no mundo, de conferir sentidos. Os primeiros trabalhadores que se instalaram nessa cidade tinham seus pés fincados nos campos arados. Para construírem a nova capital, aprenderam, no canteiro de obra, a manejar instrumentos de trabalho desconhecidos. Não importava de onde vinham essas pessoas, se do nordeste, do sul ou do próprio centro-oeste, mas importava que todos traziam consigo as marcas do Brasil rural. Assim, à medida que a cidade foi crescendo, os trabalhadores e suas famílias foram organizando, por necessidade e hábito, uma estrutura comercial que lembrava, e ainda lembra um pouco de cada lugar do Brasil.

A proposta de construir uma nova cidade com esperança de vida melhor, de uma casa e fartura de trabalho e alimento foi, aos poucos, desfazendo-se, pois os dias difíceis que acompanharam a construção não foram superados pelos trabalhadores candangos ou seus descendentes. Novos habitantes chegaram, ocupando os espaços nobres da cidade. Os trabalhadores foram acusados de invadirem áreas públicas e convidados a retornarem às suas terras. Contudo, eles já haviam fincado território, já estavam impregnados pelos desejos e esperanças prometidas e sentiam-se parte integrante daquilo que construíram.

Assim, há lugares na cidade, como a Feira do Guará, ou do Pedregoso, aonde moradores saudosistas iam em busca de um resquício do gosto do sertão nordestino: a música, a carne seca e a melodia do sotaque da terra natal. Essa é uma prática que ainda acontece na cidade. O mercado do Núcleo Bandeirante, por exemplo, é um seleto espaço para alguns nordestinos, que saem das áreas nobres onde habitam - Lago Sul e Plano Piloto - , para degustar a buchada e a típica carne de sol com seus suculentos 
acompanhamentos, ao som de sanfonas. Poderia seguir na lista, chamando atenção também para os prazeres da comida mineira e goiana e mesmo para aquelas das chamadas zonas de civilização, no eixo Rio - Paris. Contudo, deixemos esta questão para os estudiosos dos hábitos alimentares com pitadas de paladar brasiliense.

Portanto, é essa diversidade, nas configurações e reconfigurações elaboradas no cotidiano de seus moradores, que o trabalho deve ser pensado. Considerando essa gente que se instalou na cidade, apesar do indelicado convite de se retirarem após longos anos de trabalho para ver a cidade em pé, percebi que os termos "trabalho formal" e "trabalho informal" eram desconhecidos por grande parte dos trabalhadores da informalidade. Pode-se pensar, portanto, utilizando a categorização de Chaú (1980), como uma resistência que tem a cor do conformismo. Fato é que eles preferem a distinção entre o trabalhador do serviço público, detentor de várias regalias, e o trabalhador por conta própria ou que vive de "bico", que vive as agruras do presente e a incerteza do futuro.

Há uma sutileza na recusa do termo "informalidade" (THEODORO, 1998), pois a expressão "trabalho informal" deixa entrever o caráter ambíguo que possui a própria noção. Para ficar no campo historiográfico, é bom considerar o trabalho ontológico, social e culturalmente construído, e a informalidade como noções mais jurídicas do que representativas das práticas e representações individuais e coletivas.

Entretanto, para além do desconforto da expressão para esses trabalhadores, a cidade, centro do poder político e decisório do país, está cotidianamente assolada por questões que interpelam a população. Seus espaços físicos tornam-se territórios de trabalhadores que não possuem vínculo empregatício e transformam-se em lugares praticados, para ficar com Certeau (1998).

Até o início do governo de J osé Roberto Arruda ${ }^{3}$ do Partido Democratas, que assumiu o cargo em 1ํ․ de janeiro de 2007, em vários espaços vazios nas imediações da rodoviária e do centro comercial sul, ou ainda nas proximidades de escolas, hospitais e ponto de ônibus e nas passagens subterrâneas para atravessar o eixo central, na direção leste/ oeste, crescia a incidência do mercado informal. Entre as mais visíveis políticas de Arruda, destacam-se a construção e ampliação de vias públicas e a "limpeza da cidade”, isto é, o retirar das ruas os vendedores ambulantes.

Atualmente, a redução da informalidade nas áreas centrais da cidade é visível, mas ela ainda persiste em alguns pontos da cidade, principalmente nos pontos de

\footnotetext{
${ }^{3} \mathrm{O}$ primeiro ano do Governo Arruda foi marcado por decisões políticas bastante impactantes, como a proibição da circulação das vans, a derrubada de placas de propaganda não permitidas, a demolição de prédios em situação irregular e o início do processo de legalização dos condomínios.
} 
ônibus, de onde as barracas são retiradas, mas rapidamente recolocadas. A cidade é, portanto, apropriada, representada e configurada por práticas cotidianas dos grupos em desvantagem econômica e que não se recolhem às cidades-dormitórios satisfeitos com as políticas assistencialistas de provimento de pão, leite, gás, bolsa-escola.

O comércio de ambulantes foi crescendo na plataforma da rodoviária e no setor comercial sul, bem como nas proximidades do Hospital Distrital em função da demanda dos transeuntes de baixa renda que circulam por estas localidades. Por esse motivo, retirar os trabalhadores desses locais representa uma perda significativa nas suas rendas e reduz o consumo de produtos baratos das camadas populares, pois o deslocamento até a Feira Popular, construída ao lado da rodoferroviária, é muito difícil devido à longa distância e do preço das passagens de ônibus, muito caras em Brasília.

Nesse contexto, aventuro-me a falar de "Brasílias", pela pluralidade de vozes e práticas que suas largas avenidas e sua formatação em quadras e entre-quadras deixam entrever. Embora os efeitos da reestruturação produtiva sobre a vida, com riscos de desintegrar a solidariedade e as obrigações sociais tradicionais, sejam importante e objetos de inúmeras pesquisas, prefiro investigar a habilidade dos grupos de se organizarem de modo e preservar ou reinventar a manutenção dos elos sociais que permitem sua coexistência, mesmo em situação desvantajosa, isto é, mesmo em condições de precariedade, de ilegitimidade, de exclusão social. Onde carece o reconhecimento social, emerge uma "socialidade" (MAFFESOLI, 1997) que faz germinar outro espaço político. São “apreciações valorativas” (PESAVENTO, 2003) que permitem compreender um pouco mais do nosso caminhar histórico.

Reafirmo, assim, o debate teórico que abre o texto ao afiançar que a hegemonia econômica não coloca amarras no imaginário social, fértil o suficiente para reelaborar e reconfigurar o mundo vivido, do qual o trabalho faz parte. Cabe à História, como campo de conhecimento, oferecer leituras possíveis da história dos homens reais. E foi com este propósito que escolhemos enfatizar as falas e as imagens que emergem do cotidiano de Brasília, de forma a dar mais visibilidade ao que Thompson chama de a história vista de baixo. Queremos dizer que não basta olhar as políticas públicas, ou as orientações regulamentares e econômicas, para apreender as modulações das relações de poder, mas é preciso adentrar os modos de fazer e pensar dos trabalhadores informais.

Uma vez compreendia a ambiguidade que ronda o termo "trabalho", compete-nos escrutinar sua articulação nos meandros da cidade. Para isso, consideramos Brasília por sua peculiaridade, afinal, a jovem capital do país, a cidade patrimônio, não se libertou de velhas práticas ocupacionais que se imiscuem no seu cenário arquitetônico. 
Chamou-nos a atenção o resultado de entrevista semiestruturada realizada, em 2003, com habitantes de Braslândia e Águas Lindas (KUYUMJ IAN, 2003a) ${ }^{4}$, trabalhadores da informalidade. Nessa pesquisa, foi apresentada uma lista de dez itens (alimentação, saúde, água, segurança, dinheiro, coleta de lixo, lazer, família, trabalho e casa, na ordem aqui apresentada), para que os entrevistados, em um total de 122 pessoas entre homens e mulheres, enumerassem, em ordem decrescente, o que lhes era mais essencial. Três itens se destacaram como prioridades nas duas cidades: saúde, alimentação e água. Segurança, dinheiro, família e casa também apareceram com frequência razoável nas respostas. No entanto, surpreendeu o fato de, em tempos de precarização, o trabalho aparecer como o último item dos indicados na lista de prioridades. Curiosamente, a população dessas cidades tende a ser classificada na categoria de desempregados, precarizados eautônomos.

Na ausência de trabalho e qualidade de vida, na ineficácia administrativa de prover bens e serviços essenciais à comunidade, a interação do homem com o seu meio consiste em "aproveitar" ao máximo o pouco que está disponível para seu sustento, lazer e convívio comunitário. A paisagem do cerrado torna-se, nesse contexto, o meio ambiente que proporciona lenha, animais silvestres, plantas medicinais, ou seja, tudo o que pode ser transformado em valor de uso e, quando possível, em valor de troca. Porém, não se pode restringir as ações desse homem a um lamentável estado de pobreza. Deve-se considerar sua experiência da vida no campo, entre roçados e colheitas que quase todos relatam como patrimônio de um passado recente. Não vou entrar no debate sobre a relação campo e cidade na feitura e compreensão do trabalho, pois este é tema de outra reflexão.

Nas cidades-satélites, consideradas aqui como espaço de vivência, os arranjos cotidianos estão, todo o tempo, em profunda articulação com os conhecimentos acumulados de experiências passadas sobre a vida rural. Portanto, noções como as de experiências, expectativas, táticas e trajetórias, no viés analítico de Maffesoli, que identifica estratégias, táticas e astúcias como formas de driblar as dificuldades e construir uma trajetória mesmo em desvantagem ou em invisibilidade social, foram parte dos pilares teóricos para discutir a dissonância cultural no trabalho em Brasília.

\footnotetext{
${ }^{4}$ Destaco que a referida pesquisa foi realizada com o propósito de avaliar o impacto das práticas cotidianas e ocupacionais no meio ambiente. Referia-se a um projeto de grande porte e multidisciplinar, que envolvia pesquisas em áreas bem distintas como engenharia florestal e geologia. Embora motivada por outro propósito, as manifestações sobre o entendimento de trabalho em correlação com o meio ambiente, na perspectiva da sustentabilidade, foram muito elucidativas na pesquisa, refletindo sobre o trabalho em Brasília. O objeto da pesquisa sustentabilidade e consciência ecológica - sequer aparecia como uma questão para os entrevistados, o que se justifica pelo grau de carência e baixa qualidade de vida que não deixam espaço para outras demandas que, em face da necessidade cotidiana, aparecem como supérfluas.
} 
A ideia é, pois, a de verificar as marcas deixadas pelas práticas nos traços identitários e significantes desses indivíduos, o que nos detém em outra questão mais pungente: que categoria de trabalhadores a cidade reclama? Uma coisa é o trabalho regular demandado pelo estado e pelas instituições legais, outra coisa é o trabalho que mantém a dinâmica da cidade com pequenas confecções, consertos, limpezas que permitem o funcionamento de aparelhos domésticos, automóveis, residências e, diariamente, asseguraram o funcionamento do oikos como um todo. Tanto a cidade quanto o trabalho estão enredados na relação dialética do inscrever e apagar, como diz Chartier (2007). Ademais, em ambos se entrelaçam os fios do relato do historiador, os rastros dos discursos sobre a mudança da capital. Além disso, o trabalho desejado para a cidade deixa entrever "os labirintos da realidade", diria Ginzburg (2007). Labirintos nos quais os pequenos trabalhadores, figuras banais, emolduram a cidade com base em outros espaços de vivência e redesenham-na com outras tramas elaboradas pelas práticas cotidianas que se encontram nos lugares que habitam e nos que trabalham. São vozes, cores, cheiros e formas que se destoam dos traçados arquitetônicos, mas que também dizem a cidade e a faz respirar e transpirar.

Segue o olhar do historiador que, em mãos e mentes de outros pesquisadores ${ }^{5}$, detém-se nos fragmentos do cotidiano, articulando a cidade de Brasília com o universo cultural do trabalho dos candangos, importantes nas décadas de 50 e 60. Tal titulação foi dada aos recém-chegados no espaço aberto da futura cidade, mas, atualmente, é uma classificação que os desqualifica por meio do ordenamento do espaço citadino tensionado por práticas de políticas habitacionais que segregam, que permitem, aos pobres, participarem da cidade patrimônio apenas com o olhar distanciado, uma miragem vista da plataforma da rodoviária. Não mais. Imagem que remete ao filme/documentário de Vladimir Carvalho, Brasília segundo Feldman, produzido em 1979, em que um trabalhador depoente afirma que os candangos podem ir até aquele ponto, podendo até serem mortos se arriscarem ir além. Esses depoentes distantes em temporalidade e tão próximos em possibilidades, acariciam com o olhar a cidade amada e desconhecida. É nesta perspectiva que a ambiência tomada é o olhar da periferia, isto é, dos filhos de candangos que habitam as cidades-satélites. Tal perspectiva faz-nos pensar nos impactos provocados pelo rompimento abrupto das teias de relações que constituíam o cotidiano dos candangos e ainda compreender os

\footnotetext{
${ }^{5}$ Refiro-me às dissertações de mestrado, defendidas por Michelle dos Santos e por Edson Beú Luiz. A primeira, intitulada A construção de Brasília nas tramas de imagens e memórias pela imprensa escrita (1956-1960) e defendida, em 2008, na UnB, e a segunda intitulada Ceilândia e trajetórias de exclusão socioespacial: as identidades dos filhos dos candangos, defendida também na UnB, em 2007. Ambas sob minha orientação.
} 
sentimentos que seus filhos nutrem, hoje, pela capital que os pais construíram. Fora das redes hegemônicas de privilégio, certamente representam parte do contingente que vai, diariamente, ganhando trocados no trabalho informal.

Encontrei vendedores de sacos de tecidos, utilizados para confecção de panos de prato ou de limpar chão, como receptores dos produtos entregues por um terceiro. Há, ainda, aqueles que, com pouco capital, adquirem canetas e chaveiros para revendê-los nos ônibus. Outros montam ponto de corte de cabelo ao ar livre, contando com o mínimo de equipamento necessário para o desempenho da atividade - uma tesoura, um pequeno espelho de péssima qualidade, um banco tosco - e se arranjam sob a copa de uma árvore que serve também para afixar o espelho. Os mais capitalizados montam suas barracas para vender frutas, cachorro-quente, salada de frutas. Alguns, muito criativos, transformam carrinhos de picolé em aparelhagem de som portátil para anunciar os CD e DVD piratas que estão disponíveis para a venda. Outros, ainda, limitam-se a abrir um tecido no chão, em que expõem os produtos ou equipamentos de trabalhos, especialmente no caso de serralheiros e marceneiros.

São várias as táticas dos trabalhadores para se fazerem presente aos olhos do público e chamar atenção para o que desejam vender. Quanto mais capitalizado, mais refinado é o recurso de abordagem e de comportamento do vendedor. Ao contrário, quanto menos recurso financeiro dispõe o vendedor, mais ele lança mão de práticas jocosas para chamar a atenção do público. Por vezes, não há escolha: vende-se o que aparece, de acordo com a oportunidade, situação que por vezes faz rir pelo inusitado do produto, cuja utilidade é difícil de ser identificada. Porém, está lá, exposto e visto pelos transeuntes curiosos por novidades.

Alguns utilizam a trajetória dos ônibus para vender suas canetas, chaveiros, carteiras e blocos de anotações, figurinhas e pequenos brinquedos. Para isso, contam com a camaradagem dos motoristas de transportes públicos que, segundo informam os vendedores, "dão carona" porque sabem que estes estão trabalhando, tentando "ganhar a vida". Há, logo, certa cumplicidade entre vendedores e motoristas, de modo a resguardar a integridade destes quando da chegada de fiscal da linha de transporte público.

Oportunamente, instamos o leitor a considerar essa linha do tempo que vai dos debates sobre a construção da capital à atualidade dos trabalhadores informais. Os diálogos tête-à-tête dos tempos idos com o presente se nos apresentam franqueados pela ideia de Braudel (1978, p. 286) de que "É do conflito - ou da harmonia entre atitudes antigas e necessidades novas - que cada povo faz diariamente seu destino, sua 'atualidade'." É neste mesmo autor que encontramos a preocupação com a 
complexidade do homem, com a própria vida, e a aclamação pela aplicação, nos domínios da História, da noção de realidade "entrecruzada".

O lastro do entendimento da problemática que se coloca se amplia e ganha adesão de novas categorias nocionais que permitem alargar a compreensão do universo urbano da capital do Brasil em relação ao trabalho. Do mesmo modo que Bouvier (1991) assinala que se pode identificar, no período do Egito Antigo, a hierarquização e intelectualização de certas tarefas, servindo para distinguir os trabalhadores pelo menos nas cidades tendo, numa ponta, o camponês e, na outra, o escriba e, entre eles, os trabalhadores de valores intermediários, como pedreiro, menuisier, orfévres e artistas, podemos identificar, na contemporaneidade, divisões no mundo do trabalho que interferem no grau de reconhecimento social. Isso nos conduz, como corretamente insiste Demo (1994), na gradação da cidadania entre a tutelada e a emancipatória. Esta última se realiza pela inclusão adequada no mercado de trabalho e na cidadania. Quando é necessário fazer acionar os instrumentos da assistência social, significa que o direito fundamental dos indivíduos de se autossustentar não se realiza porque o Estado não consegue enfrentar o problema da pobreza estrutural.

De certo modo, esses indivíduos reconhecem os limites estruturais do Estado brasileiro, mas não reproduzem o discurso desse Estado da necessidade de formalizar o informalizado. Sabem que não há trabalho formal para todos e, ainda e mais importante, não se identificam como informais. Para um entrevistado, a distinção é entre os que trabalham e os que não trabalham. Ele vislumbra o trabalhador de duas maneiras distintas: aqueles que não conseguem se manter em uma atividade comercial, por mais simples que seja, por falta de tino comercial, por abordagem inadequada ao cliente, por estar sempre na mira da fiscalização, pelo ponto de negócio pouco promissor, produto pouco interessante ou de baixíssima qualidade, mal gerenciamento das contas, ou por problema de doença pessoal ou de algum parente próximo como filho, esposa 6 .

A segunda distinção que ele faz, e é também apontada por outros entrevistados, refere-se àqueles que não se empenham no trabalho para ganhar seu próprio dinheiro. Neste caso, o discurso proferido vai em direção à preguiça, ao estar encostado na "pobre mãe", ao não querer nada com a dureza. Insistem que quem quer trabalhar sempre acha alguma coisa para fazer, pois trabalho não falta, o que falta é dinheiro e emprego, numa referência à distancia entre trabalho e emprego.

\footnotetext{
6 Observa-se que há, entre eles, noções essenciais de administração e de contabilidade para o gerenciamento do negócio.
} 
Além disso, esses trabalhadores informais estão imbuídos de princípios morais, pelos quais revelam o valor do trabalho em contraposição a atividades ilícitas. Dizem que é preferível trabalhar do que roubar; é preferível ganhar pouco do que não ganhar nada, afinal, "mais tem Deus pra dar do que o Diabo pra levar"7. Com essas palavras, reforçam a ideia de que não se consideram fora da legalidade, não se vêem como suspeitos. Contrariamente, reclamam a dignidade que merecem, o reconhecimento que o trabalho deveria lhes conferir.

Observa-se, assim, que o Brasil não realizou a passagem do operariado-produtor para o assalariado-consumidor. A informalidade é o reflexo do desejo de compartilhar bens e produtos que são inacessíveis para as camadas mais pobres, com salário mínimo na razão de $\mathrm{R} \$ 510,00$, o que equivale a aproximadamente 32 vezes menos que a renda média do brasiliense, isto é próximo a R\$17.000,00.

Assim, observam-se leituras diferenciadas de um mesmo universo o trabalho. Os trabalhadores não identificam a existência de dilemas econômicos, mas sociais. Avaliam que o Estado pouca atenção dá aos trabalhadores pobres. Como consequência desse abandono, fica sob a responsabilidade do trabalhador o ônus do trabalho, muito pesado e sem cobertura institucional.

Os trabalhadores informais vivem as marcas que a industrialização imprimiu neles, criando enclausura para os homens e seus fazeres. Realçar o que pensam esses trabalhadores abre o lastro do conhecimento para as afinidades e a solidariedade que configuram e acomodam sentimentos e interações. Mesmo que trabalhar em troca de salário represente uma das mais fortes imposições da sociedade de mercado, há, no sistema, zonas obscurecidas que demonstram que a integração no sistema de produção nunca conseguiu garantir a coesão social.

As sociedades se organizam também em torno de outros valores e o Estado necessita prover a sociedade, principalmente os grupos mais vulneráveis, com argumentos que evoquem a diversidade humana e alastrem a noção de necessidade. Quanto ao mercado, permanece como reino das incertezas porque, a cada dia, surgem novas atividades cuja distância entre finalidade mercadológica e sobrevivência não é facilmente apreendida.

O declínio do trabalho industrial e a nova divisão global do capital deslocam parte significativa da mão de obra para atividades informais. Dessa forma, a sociedade industrial moderna cria uma situação alarmante, passando a mensagem de que o desenvolvimento se faz pelo trabalho, mas não com qualquer trabalhador. O fosso que

\footnotetext{
${ }^{7}$ Informação verbal de um dos entrevistados para o desenvolvimento da pesquisa do qual este artigo é um dos produtos.
} 
separa os formais dos informais é um forte indicador de que os trabalhadores, diferentemente do trabalho, podem ser dispensados. Nesse sentido, Brasília nasceu sob esta espada: a dos que pensavam que, com o trabalho e as generosas palmadinhas nas costas vindas de J uscelino Kubitschek ${ }^{8}$ teriam acesso a uma parcela da cidade. Ao contrário, foram dela expulsos. Esta experiência coletiva e encravada na memória impede a credibilidade do Estado, que reatualiza e reproduz sentidos "já-dados".

São as nervuras e as fraturas do tecido social que demarcam lugares específicos para diferentes vínculos sociais, marcados por diversas sinergias. Os trabalhadores informais são uma forte expressão da realidade contemporânea, desdobramento do desenvolvimento do processo produtivo, e o espaço econômico, sob a batuta dos comandantes das grandes empresas nacionais e internacionais, vão dando o tom e o ritmo da organização do trabalho, da classificação dos postos de trabalho. Ao mesmo tempo, aproveitando a sonoridade dessa orquestra bem ensaiada, outros espaços vão sendo criados e recriados, sob os pés e batuques dos trabalhadores que redimensionam sua participação nas sobras e franjas das atividades disponíveis, como no remix de um talentoso DJ (disc jockey) que vai misturando novos sons aos sons da orquestra, e o que parece dissonância ganha novo sabor, nova musicalidade, novo modo de apreciar e viver a vida, insisto, mesmo que em desvantagem socioeconômica.

\section{Referências}

BARBOSA, J air. Apresentação: um livro que embriaga. In: SCHOPENHAUER, Arthur. O mundo como vontade e como representação. São Paulo: Unesp, 2005. t. 1.

BAUDRILLARD, J ean. L'échange symbolique et la mort. Paris: Gallimard, 1976.

BERMAN, Marshall. Tudo que é sólido desmancha no ar: a aventura da modernidade. São Paulo: Companhia das Letras, 1986.

BOUVIER. Pierre. Le travail. Paris: Presses Universitaires de France, 1991. (Coleção: Que sais-je?)

BRAUDEL, Fernand. Escritos sobre a história. São Paulo: Perspectiva, 1978.

CASSIRER, Ernest. Linguagem e Mito. Sáo Paulo: Perspectiva, 2006.

CERTEAU, Michel de. A Invenção do cotidiano I: artes de fazer. Petrópolis: Vozes, 1998.

CHARTIER, Roger. Inscrever e apagar: cultura escrita e literatura (séculos XI-XVIII). São Paulo: UNESP, 2007.

\footnotetext{
8 Imagem fílmica contida no documentário de Vladimir já mencionado anteriormente.
} 
CHAUÍ, Marilena. Cultura e democracia: o discurso competente e outras falas. São Paulo: Moderna, 1980.

COELHO, Teixeira. Dicionário crítico de política cultural: cultura eimaginário. São Paulo: Iluminuras, 1997.

D’EPINAY, Christian Lalive. Significations et valeurs du travail, de la societé industrielle à nous jours. In: DE COSTER, Michel; PICHAUTL, François. Traité de sociologie du travail. Bruxelles: De Boeck Université, 1994. p. 55-82.

DEMO, Pedro. Política social, educação e cidadania. Campinas: Papirus, 1994.

GINSBURG, Carlo. O fio e os rastros: verdadeiro, falso, fictício. São Paulo: Companhia das Letras, 2007.

HOBSBAWN, Eric J . História social do jazz. 2. ed. Rio de J aneiro: Paz e Terra, 1990.

KUYUMJ IAN, Márcia de Melo Martins. Brasília e a representação do meio ambiente na encenação cotidiana. In: SIMPÓSIO NACIONAL DE HISTÓRIA, 22., 2003, J oão Pessoa. Anais... J oão Pessoa: Guia J P, 2003a. v. 1. p. 0-9.

. Descompasso entre lei e realidade: trabalho e proteção social. In: FERREIRA, Mário César; ROSSO, Sadi Dal. (Org.). A regulação social de trabalho. Brasília: Paralelo 15, 2003b. v. 1.

KUYUMJ IAN, Márcia de Melo Martins; LINS, Cilene Sebastiana Braga. Pobreza e transgressão: trabalho informal feminino na capital federal do Brasil. In: STOLCKE, Verena; COELLO, Alexandre (Ed.). Identidades ambivalentes em América Latina [siglos XVI XXI]. Sevilha: Bellaterra, 2008. p. 151-172.

LEGROS, Patrick; MONNEYRON, Frédéric; RENARD, J ean-Bruno; TACUSSEL, Patrick. Sociologia do imaginário. Porto Alegre: Sulinas, 2007.

MAFFESOLI, Michel. Transfiguração do político: a tribalização do mundo. Porto Alegre: Salinas, 1997.

MARX, Karl. Manuscritos econômicos e filosóficos. São Paulo: Martin Claret, 2005.

MORIN, Edgar. A unidade do homem. São Paulo: Cultrix, 1982.

PESAVENTO, Sandra J atahy. História e história cultural. Belo Horizonte: Autêntica, 2003. v. 1.

SAHLINS, Marshall. Âge de Pierre: âge d'abondance. Paris: Gallimard, 1976.

SODRÉ, Muniz. Claros e escuros: identidade, povo e mídia no Brasil. 2. ed. Petrópolis: Vozes, 1999.

THEODORO, Mario Lisbôa. L'intervention étatique sur l'informel au Brésil. 1998. Thèse (Docteur) - l’Université Paris, Paris.

TOURAINE, Alain. Crítica da modernidade. Petrópolis: Vozes, 1994. 
VEYNE, Paul. O império romano. In: . (Org). História da vida privada 1: do império romano ao ano mil. São Paulo: Companhia das Letras, 1989. p. 7-212.

Colaboração recebida em 02/ 06/ 2010 e aprovada em 12/ 09/ 2010. 